\title{
"Seeking" or "ground" --- study of the current vocal music teaching for minority students
}

\author{
Aihua Guan \\ Music and Dance College, Beifang University of Nationalities, Yinchuan Ningxia, 750021, China
}

Keywords: Minority students, Vocal music teaching, Diversification.

\begin{abstract}
At present, the vocal music teaching is very single in the teaching content and form in China's colleges, because the "western music center theory" and "China music center theory" are still subconsciously affect our teaching activities. Then, the songs of our minority areas are neglected, especially part of works which is sang in the minority language or local dialect. The ethnic property of many minority students has been even neglected so that their language, aesthetic habits and singing modes have been changed. As a result, due to the change in their singing modes, many very talented minority students get lost in their purpose of vocal music learning. As for the advanced vocal music teaching, educators should not establish a teaching system according to their likes and dislikes but should cultivate talents under the vision of cultural diversity. Only in this way, can they make contributions to the powerful cultural country.
\end{abstract}

\section{Introduction}

China is a multinational country, where the 56 nationalities co-created the great Chinese civilization after the great integration of nationalities for thousands of years. Besides, Chinese civilization is the starting point and foothold nourishing our artistic creation. In this sense, arts created by all nationalities can be called Huaxia arts or Chinese arts, because they have the distinct uniformity. However, people in all regions of China also created the artistic forms which comply with their own aesthetic habits, value tendencies and means of expression of their regions or nationalities after living and production for ages. Especially, all the minority compatriots have created rich, colorful, extraordinary and magnificent folk songs, most of which have become one of the precious members in the gene pool of Chinese arts (such as "Wahaha", a song of Uyghur nationality). This also reflects the colorfulness of Huaxia arts from the other aspect. In our country, many nationalities don't have their own writing system, so ethnic songs play a role in inheriting the national culture, humanistic feeling, lifestyle, custom and moral standards etc. It is exactly such protogenetic ethnic songs that become our libraries to reversely explore the sources of histories, cultures, living habits and production modes of minorities.

Higher art education is an important link of cultural inheritance and development. As far as inheritance is concerned, it is required to not only understand and learn the cultures and arts of all nationalities in the world but also deeply understand, learn and study the cultures and arts of all minorities; otherwise, the so-called "powerful cultural country" will only be a castle in the air. In higher art education, vocal music education is an important part of music education. The currently relatively single form or content in China's vocal music education, the long-term emphasis on the training of techniques and skills and the insufficient training of musical aesthetics have resulted in the single thinking of vocal music teaching. Especially, systematic training and teaching guarantee for songs in minority languages and minority students are not available now and many so-called minorities' vocal music educations are only individual mutual explorations by teachers and students. Therefore, it is badly in need of adding the teaching and aesthetic research of minority songs in vocal 
music teaching in colleges, especially those located in minority areas. The emphasis of this work is how to adjust the dialectical relationship between "difference" and "similarity" in vocal music teaching, and is also the process to rationally and freely exchange the thinking mode of "teaching" and "learning" in minority vocal music on the background of two or more cultures. Because of the research on this topic, the author found the problems below through his teaching for more than ten years.

\section{Problem one: the lack of system teaching concerning minority songs, language and aesthetics leaded to minority students' loss of objective and direction in vocal music singing and learning.}

As an art of music and language, the vocal music art can show its artistic quality of its unique background only when it is established on a specific cultural basis. As the saying goes, "each place has its own way of supporting its own inhabitants" and "customs are different area from area, even in a quite short distance". As all minorities are different in their production modes, lifestyles, historical backgrounds, language difference, manners and customs etc., they have formed their own characteristics national cultures which are rich in content and diversified in forms. The national folk singing arts based on national cultures are the most direct embodiments. Such national folk singing arts, which are the portraits of nationalities' spiritual worlds, not only reflect the histories of these nationalities but also provide directions for the development of nationalities, so it is required to protect, inherit and develop such arts.

Chinese civilization was completed jointly by 56 nationalities, which jointly composed the rich artistic chapter of Chinese national vocal music. Based on the uniform national artistic temperament, the music singing styles of all nationalities show different and unique characteristics. They express their own production modes, aesthetic tastes and humanistic feelings with their own music and languages. Such excellent national folk songs are the links to maintain national sentiments, the windows for us to understand different artistic styles and also the material bases for the young generation to inherit national cultures.

Nowadays, there is no lack of some minority students or those from remote rural mountainous areas learning vocal music with their own singing habits and performance methods inherited from generation to generation in colleges, especially those located in minority areas. However, there are usually conflicts among their singing methods, means of expression and the current mode of vocal music teaching in colleges, so controversies often arise in their folk songs and singing modes with local and national characteristics. Such artistic styles usually exceed some music educators' so-called cognitive scope of vocal music art, so they change them with the so-called standard voice and it is normal for minority students in vocal music teaching to be asked to follow our habitual aesthetic standards for vocal music. Secondly, the current college vocal music education system has a power right of speech and has the absolute authority over the evaluation system and standards, so some minority students begin to doubt their own signing modes, think their voices are "rustic" and "not pleasant to the ear", gradually lack confidence in vocal learning and singing, and thus initiatively give up further learning and research of their own national singing modes and songs. Then, they yield to the current vocal music education system, change their so-called "bel canto" or "folk-style singing", and thus lose their own nationalities' singing characteristics, folk songs, artistic self and individuality of art.

\section{Problem two: the "standardization" and "homogenization" reflect the widespread current situation of teaching for national vocal music major in China's colleges}

At present, in the vocal music teaching system of all colleges, the western teaching methods are mostly adopted in the training of vocal music skills and works is mostly sang in mandarin, Italian and German etc. It is undeniable that the western vocal music teaching system based on anatomy plays a role in actively developing our national vocal music and promoting it to go to the world. However, under the influence of western music for a long time, our vocal music education system is used to the standardized teaching means, methods and principles in compliance with the western music aesthetics. Many minority languages with local colors and local dialect songs are not included and 
even neglected and forgotten by our national vocal music classrooms. Most vocal music teachers' emphasis on singing styles and skills outdistances the emphasis on our national styles and characteristics, neglect the students who came from the remote minority areas and sing in their national dialects, and adopt the uniform teaching mode for such so-called minority group of students. Besides, some teachers subconsciously have bias against those students who sing in their own national dialects and think that it is required to accept scientific training and singing of artistic works with the uniform teaching mode in colleges; otherwise, they think that such students' singing modes are not scientific and fail to comply with the music education mode in colleges. All of these have severely affected minority students' judgment and identification over the art of singing so that they lose the ability to sing their national songs on the premise of correctly mastering the national styles. As time passes, such "special" students' concept is also changed and they lose the interest in singing the songs of their own nationalities, consider their singing modes as unscientific ones, gradually lose the interest in singing the songs in their own national languages or local dialects and thus they will try to change their singing styles and characteristics of their voices. This is the most root cause for the phenomenon that a thousand persons sing in the same style today.

In addition, there are a very low proportion of minority songs in the current national vocal music teaching materials. The insufficient amount of works fails to correctly deliver a nationality's artistic style and understanding in vocal music art and results in that students fail to profoundly understand the characteristics, styles and connotations of traditional music cultures of Chinese minorities so that it is very difficult for students to form their own singing styles and characteristics in national vocal music singing.

The author found, in vocal music teaching, that most minority students sang their own national songs with a fluent expression of voice, natural high pitch, free and easy application of some run-cavities with their national and local characteristics, significant artistic quality and individuality. However, once they were trained with our coherent teaching mode, they would have a lot of problems such as stiff breath, failure to reach the high pitch, non-uniform pronunciation and tone etc. Then, in the class, both the teachers and students feel exhausted; the students fail to meet the teacher's requirements while the teacher also feel puzzled. As time passes, students also lose interest in singing. As a matter of fact, art education, which is not an industrial product, cannot be produced according to the so-called standard. Vocal music teaching should follow the characteristics of individualized teaching more thoroughly. When Tseten Dolma, a Tibetan singer, was a student in Shanghai Conservatory of Music, her teacher's teaching positioning of her was "national characteristics and scientific singing". Therefore, after learning for several years, Tseten Dolma not only didn't lose her characteristics of Tibetan songs but also showed stronger expressive force of voice. Thus, it is required to give more guidance with individuality and nationalized educational thought while stressing scientization.

\section{Solutions to the problems in minority vocal music education}

\section{"Reserving difference" is one of the approaches to change the unicity of national vocal music teaching.}

Art is "diversified" instead of "single". Art education should also comply with this principle. Art also has the national character, pursuing art without considering its national character is just a fruitless approach. In vocal music teaching, we should teach students in accordance with their aptitudes rather than make changes in a blind way. Artistic individuality is an individual artistic worker's specific understanding and expression of art and is the mark for the maturity of an artistic life. Mutual imitation is increasing in the current signing of Chinese national vocal music. Some criticize that "a thousand persons have the same face and ten thousand persons have the same voice". As a matter of fact, apart from that the signer has his unique understanding of the work in vocal music singing, one's own voice is the most visual media to show one's artistic individuality. One who has the most distinctive voice will show the most noticeable artistic individuality. Under the influence of different 
cultural traditions and aesthetic habits, the majority of minorities in China show greatly different tone expressions in singing. Many singing modes full of characteristics are the markers to distinguish different nationalities, such as the Mongolian long tune and unique trill in "Huaer" singing style. Due to the unconscious influence from childhood, the songs and singing modes left by their ancestors have been early rooted in their cultural genes, so students which sing their national songs should be encouraged more; besides, we should excavate their singing advantages and conclude their scientific sides for compact development instead of change them.

\section{Strengthening the understanding of national culture is the foundation of national vocal music teaching}

Minority students are obliged to let more people to understand their own music and cultures. Minority cultures and arts can equally participate in exchanges only after they are systemized and generalized by those talents who have accepted professional training. In college vocal music education, students not only need to learn some skills but also need to learn the humanistic spirit of equality and tolerance; they should pursue the individualized artistic temperament, not be sequacious and arrogant and not echo the views of others. In addition, with the cultivation of comprehensive quality in colleges, teachers can enrich their music horizon, help them to understand that they shoulder the mission of effectively inheriting and protecting their national music cultures and enhance their cultural confidence. The uniqueness and peculiarity of art is the object pursued by artists. One can show his individuality of art only by laying the roots in the most familiar artistic environment; thus, the chain of our folk music culture cannot be broken.

Colleges' national vocal music teaching, which is an important part of college vocal music teaching, clearly aims to cultivate talents for the development of Chinese national vocal music, which also has a explicit standard; namely, it is required to comply with Chinese people's aesthetic and hearing habits. College vocal music education must be construction on the basis of educational thought and break through some old concepts; especially, for minority students, teachers need to teach them based on their national character and their specific singing characteristics. Besides, college vocal music education need to guide them to love the songs and singing modes of their nationalities and also need to perfect this thought in the evaluation system. The vocal music art can develop only when it is raised to the height of culture. Neither imitation nor deviation is the goal of an art. The vast teachers, students and minority students who get engaged in Chinese national vocal music teaching and signing should actively shoulder the obligation of safeguarding the sovereignty of national music. Only in this way, can the national cultures not get lost in the tide of globalization.

\section{Acknowledgement}

This paper is the result of Correct Construction of Minorities' Song and Dance Aesthetics in the Process of Urbanization - Taking the Current Song and Dance of "Huaer" of Ningxia for example, early training project of art of national social science fund of 2014 in Beifang University of Nationalities. Project No.: 2014QSYP02

\section{References}

[1] Liu Zhengwei. Morphology of Chinese National Music, Chongqing: Southwest China Normal University Press, 2007-8-1.

[2] Cheng Tianjian. Introduction to Chinese National Music, Shanghai: SHCM Press, 2004-2-1.

[3] Cui Ruiying. vocal music and sound pronunciation, Beijing: China Drama Press, 2006-12-1.

[4] Zheng Maoping. Linguistics of vocal music - book series of new discipline of vocal music art education, shanghai: Shanghai Music Publishing House, 2007-4-1. 
[5] Che Shaoliu and Zhang Guixian. Academic articles on western Yunnan - study on national vocal training and talent cultivation of colleges in border areas, Yunnan: Yunnan University Press, 2008-12-1.

[6] Zhou Qingsheng. Study on Chinese national linguistics, Beijing: Social Sciences Academic Press, 2008-7-1.

[7] Zhang Junren. Study on minorities in northwest China, shanghai: Shanghai Music Publishing House, 2010-4-1.

[8] Wang Feng. Exploration on the theories and teaching of modern national vocal music, Beijing: China Books Press, 2015-3-1.

[9] Zhao Yan, Qin Qisheng and Zhu Yingchun. Theories of national vocal music and artistic expression, Jilin: Jilin University Press, 2012-5-1.

[10] Shi Weizheng. Waling out of the misunderstanding of national vocal music - body structure and aesthetics of Chinese national music, Beijing: People's Music, 2008-7. 